\title{
FINITE ELEMENT ANALYSIS OF DOUBLE WEDGE ANGLE RING FLANGE JOINT UNDER BENDING MOMENT
}

\author{
Zhang Yu, Chen Qing* \\ Power Engineering and Engineering Thermophysics, Jilin Institute of Chemical technology, Chengde Street, Jilin City, Jilin, China. \\ *Corresponding Author Email: chenqing0787@126.com
}

This is an open access article distributed under the Creative Commons Attribution License, which permits unrestricted use, distribution, and reproduction in any medium, provided the original work is properly cited.

\section{ARTICLE DETAILS}

\section{Article History:}

Received 26 June 2018 Accepted 2 July 2018

Available online 1 August 2018

\begin{abstract}
Industrial equipment is going to take a turn for the higher parameter and larger scale. It raise taller requirement to the reliability of the sealing structure. So, the new sealing structure has been paid more and more attention in practice. In this paper, the ABAQUS was utilized to calculate the sealing performance of novel and standard double wedge angle ring gasket joint under the bending moment. The novel double wedge angle ring gasket joint was smaller than standard one. The calculation results of novel structure were compared with standard structure under the series of bending moments. The results illustrated that under the same bending moment, the stress distribution of novel structure on the sealing surface was more uniformly than standard structure. The maximum gasket contact of novel structure was $67 \%$ larger than the standard structure. The deflection angle of the novel structure and standard structure were not more than 0.001 ,it was lower than the ASME standard criteria 0.3 degree. According to the JB4732, two type structures were safety under the service conditions.
\end{abstract}

\section{KEYWORDS}

Double wedge angle ring gasket, External bending moment, Sealing performance, Finite element analysis.

\section{INTRODUCTION}

The bolted flange connection is often used for the detachable connection of process equipment and pipelines. It is widely used in refinery equipment, oil and gas transmission and other industrial equipment [1]. With the development of industrial equipment in the direction of high parameterization and large-scale development, the requirements for the reliability of the sealing structure are getting higher and higher. New types of flanged joints of the sealing structure are more and more important in practical applications. Double wedge angle ring gasket flange Due to its advantages of good self-tight sealing performance, compact structure, and easy installation, the joint is a new type of flange joint that has received much attention in recent years.Kurokouchi [2], Madazhy [3], Gardner [4] and others proposed the wedge-shaped metal ring pad structure earlier. Through a series of simulation studies, it has been found that this new type of ring gasket flange joint has a better structure than traditional gaskets. High contact pressure and good sealing stability; In 2009, the United States Taper-lok Company developed a double wedge angle ring gasket bolted flange joint [5] for the high sealing requirements of subsea pipelines;In China, this new type of flange joint is used in submarine pipeline connections, such as the Penglai PL19-3 oilfield second stage subsea pipeline [6] and the Nanhai Xijiang merger project [7]. The engineering practice shows that the new structure of the flange Wide prospects for application in China's ocean engineering.Lu Xiaofeng and Xu Yongjie [8] proposed the structural parameters of the ring gasket for the follow-up study, aiming at the effect of the change of structural parameters of the double wedge angle ring gasket on the seal contact contact pressure of the ring gasket and the stress on the flange joint of the double wedge angle ring gasket ;Lu Jun and Lu Xiaofeng [9] established the selection of lightweight flange structure parameters for double wedge angle ring flange bolt flange joints and reduced the weight of the flange body, which is of great significance to the actual production.

Bolted flange joints are subjected to external bending moments in addition to the internal pressure in the pipeline, and the external bending moments are usually the main cause of the failure of the flange joints directly, sometimes causing major safety accidents, resulting in economic losses and environment. Pollution and a series of problems.At present, there are no reports on the research work on the double-wedge angle gasket flange joint under the effect of external bending moments at home and abroad.

This paper uses ABAQUS finite element software to analyze the sealing performance of the flange joints with double wedge angle ring gaskets under external bending moments, and compares them with the light-size double-wedge angle ring gasket flange joints under the same working conditions., It has important practical significance to popularize and apply the double wedge angle annular gasket flange joint.

\section{MODEL AND MATERIAL PARAMETERS}

In this paper, according to ASME B16.5-2009 [10], NPS 3"Class300 Neck Welded Flange is used. The fastener is $8 \times$ M20 studs. The gaskets are double wedge angle ring gaskets, flanges and gaskets. The dimensions are shown in Figure 1. Double wedge angle ring pads, bolts and flange material parameters [11] are shown in Table 1. 
Table 1: Material performance parameters [11]

\begin{tabular}{|l|l|l|l|l|l|l|}
\hline element & Grade & $\begin{array}{l}\text { Elastic } \\
\text { Modulus } \\
(\mathrm{MPa})\end{array}$ & $\begin{array}{l}\text { Poisson's } \\
\text { ratio }\end{array}$ & $\begin{array}{l}\text { Yield } \\
\text { Strength } \\
(\mathrm{MPa})\end{array}$ & $\begin{array}{l}\text { tensile } \\
\text { strength } \\
(\mathrm{MPa})\end{array}$ & $\begin{array}{l}\text { Allowable } \\
\text { stress (MPa } \\
)\end{array}$ \\
\hline $\begin{array}{l}\text { Double Wedge Angle } \\
\text { Ring gasket } \\
\text { flange } \\
\text { bolt }\end{array}$ & $304 \mathrm{~L}$ & 213000 & 0.3 & - & - & - \\
\hline
\end{tabular}

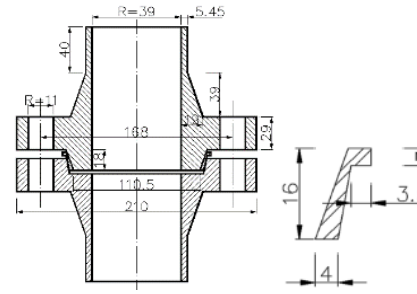

(a) Standard flange and ring pad size

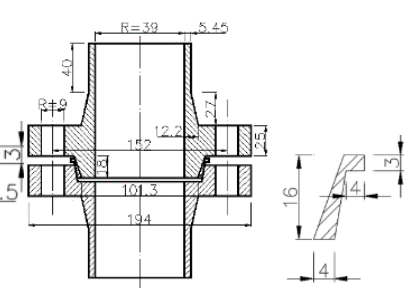

(b) Lightweight flange and ring gasket size
Figure 1: Dimensions of the flange joint and a double-tapered gasket

\section{FINITE ELEMENT MODEL}

The finite element analysis model was established using ABAQUS software. Since the flange seal joints are axisymmetric structures, taking into account the bending moment, the $1 / 2$ model of the overall flange joint was selected as the research object, and the symmetry plane of the model was set symmetrically. The cylinder end is fixed.In order to avoid the boundary effect, the length of the take-over length of the calculation model is greater than $2.5 \times(\mathrm{R}$ is the take over radius; $\mathrm{T}$ is the thickness of the take over) [12].

$$
W_{p}=0.785 G^{2} P
$$

In the formula: $\mathrm{Wp}$ is the pre-tightening force of the bolt under the operating state, $\mathrm{N}$; $\mathrm{G}$ is the diameter at the location of the reaction force of the gasket, $\mathrm{mm}$; $\mathrm{P}$ is the design inner pressure, $\mathrm{MPa}$. The internal pressure of the bolt flange joint is $5 \mathrm{MPa}$, which is equivalent to the axial force effect due to internal pressure. An equivalent pressure of $\mathrm{Peq}=\mathrm{PR} /(2 \mathrm{~T})$ is applied to the end face of the cylinder. In order to understand the sealing performance of flanged joints under different external bending moments, external bending moments of different sizes are applied to the end faces of the flanged joints, and the values are respectively 500, 1000, 1500, 2000, and $2500 \mathrm{~N} \cdot \mathrm{m}$.In the contact properties, the contact pair selected small slip and point-to-point contact with a friction factor of 0.15 [13]. All units are solid units, using C3D8R units. The meshing is shown in Figure 2.
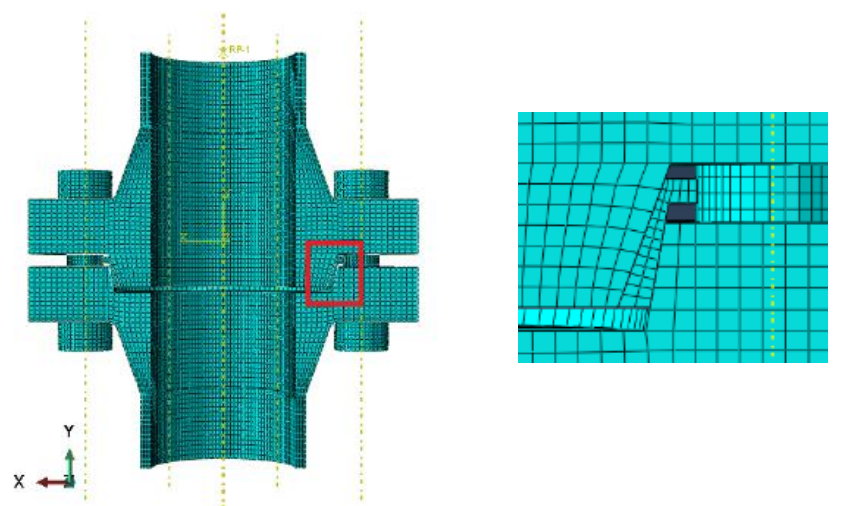

Figure 2: Mesh of the standard double wedge angle gasket flange joint

\section{RESULTS AND DISCUSSION}

4.1 Analysis of Contact Stress and Effective Sealing Width of Ring Gasket Sealing Surface

Due to the effect of the external bending moment, the stress distribution of the ring pad in the circumferential direction is not uniform, the pressure of the gasket on the pressure side of the flange increases under the action of the external bending moment, and the pressure of the gasket on the other side decreases, to ensure the flange For the sealing performance of the joint, the paths A and B are selected on the main and slave sealing surfaces on the side where the gasket is under pressure as shown in Figure 3 , and the contact stress and the seal width are analyzed. The effective seal width of the gasket refers to the width of the gasket corresponding to the seal surface of the gasket when the contact stress is greater than $\mathrm{mp}(\mathrm{m}$ is the gasket coefficient and $\mathrm{p}$ is the pressure in the medium), that is, the stress region corresponding to the upper portion of the straight line in the figure, where $\mathrm{m}=5.5[14], \mathrm{p}=5 \mathrm{MPa}$. Figure 4 shows the distribution of contact pressure between the main flange and the sealing surface of two types of flanges acting on different bending moments along paths $\mathrm{A}$ and $\mathrm{B}$. It can be seen from Fig. 4(a) and (b) that the maximum contact pressures of the main and secondary surfaces follow. As the moment increases, under the same bending moment, the maximum contact stress of the main and secondary sealing surfaces of the ring mat of the lightweight double wedge angle ring flange is greater than that of the ring gasket of the standard double wedge angle ring gasket flange. The maximum contact stress of the sealing surface, Figure 5 shows the change of effective sealing width and bending moment of the main ring and the back face of the two rings. From Figure 5(a), the effective sealing width of the main surface increases with the increase of the bending moment. When the bending moment exceeds $1500 \mathrm{~N} \cdot \mathrm{m}$, the sealing width of the main surface of the ring pad of the standard double wedge angle flange tends to be stable. The sealing width of the main face of the ring pad of the lightweight doublewedge flange continues to increase. From Figure 5(b), it can be seen that compared with the influence of the bending moment on the major surface of the ring pad, the influence of the bending moment on the surface is much smaller, and the ring gasket of the standard double wedge angle flange effectively seals the width with the bending moment from the surface. The increase shows the trend of decreasing first and then increasing, and the ring gasket of the lightweight flange shows a downward trend from the increase of the bending moment. Under the same bending moment, the maximum contact pressure and the effective sealing width of the ring gasket of the lightweight double wedge angle flange are larger than the standard double wedge angle flange. This is due to the relative reduction of the overall size of the lightweight double ring wedge flange gasket. The contact area is also reduced. As a result, the degree of squeezing on the ring pad increases, which causes the maximum contact stress and the effective sealing width of the ring pad to increase, and the maximum contact stress value of the main and secondary sealing surfaces increases as the bending moment increases. With the increase, the width of the main sealing surface of the gasket is obviously increased, and the width of the sealing surface is slightly reduced and tends to be stable. This also fully shows the superior sealing performance of the double wedge angle ring flange joint under the bending moment. 


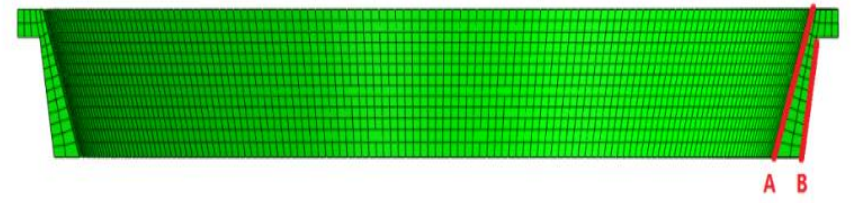

Figure 3: Contact pressure extraction path of ring gasket face

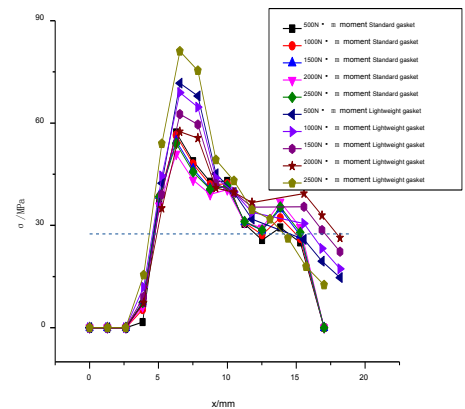

(a) Ring gasket main sealing surface

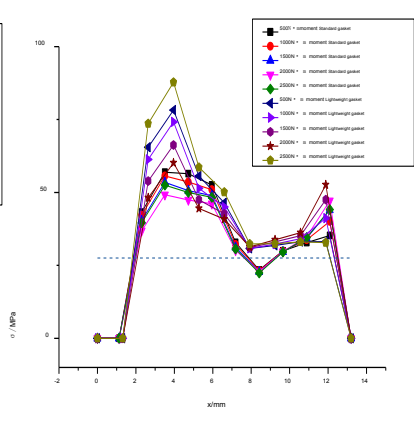

(b) Ring gasket slave sealing surface
Figure 4: Contact stress of ring gasket surface with different bending moment

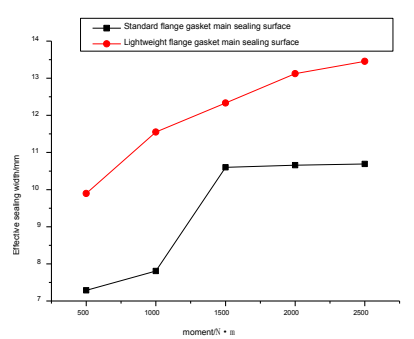

(a) Ring gasket main sealing surface

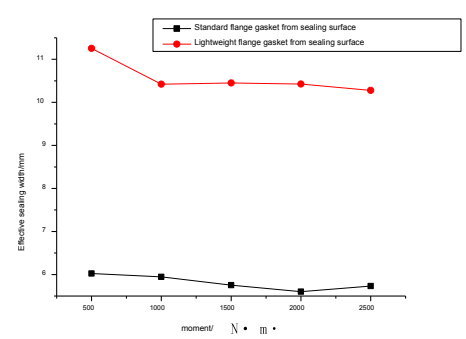

(b) Ring gasket slave sealing surface
Figure 5: The effective sealing width of the ring gasket with different bending moment

\subsection{Flange displacement and corner}

ASME VIII-1 [15] in 2010 defines the flange angle with the stiffness index "J". For integral flanges, limit the corner angle to no more than $0.3^{\circ}$.The calculation of the deflection angle can be approximated by dividing the displacement difference between the inside and the outside of the flange by the flange thickness [16]. Fig. 6 shows the variation of the deflection angle of the two flanges with the bending moment. Under the same bending moment, the turning angle of the lightweight flange is larger than the standard flange. With the increase of the bending moment, the angle of the flange is also increased. Because the effective thickness of the lightweight flange is relatively small, and the flange stiffness decreases with the decrease of the effective thickness, which results in the reduction of the deformation resistance of the flange, and the deflection angle of the flange increases under the bending moment. However, they are not more than $0.3^{\circ}$ and meet the requirements of ASME.

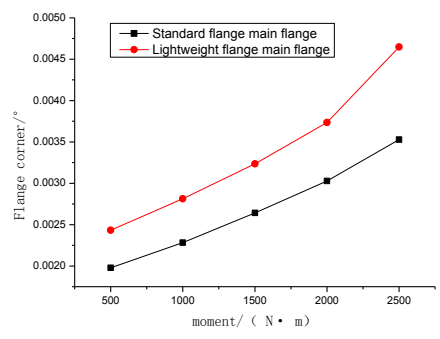

(a)The change of the main flange deflection angle with bending moment

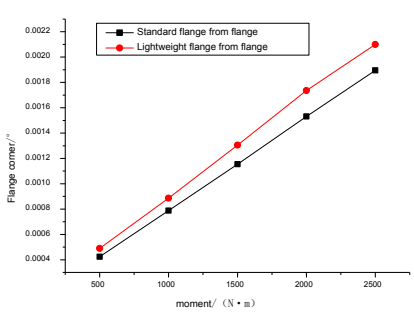

(b)The change of the bending moment
Figure 6: Deflection angle of flange under different bending moment

\subsection{Flange stress intensity assessment}

Based on structural integrity requirements, the stress of the flange structure must be within the allowable stress range of the material. Therefore, according to JB 4732-2005 "Steel Pressure Vessels - Analytical Design Guidelines" [17], the third strength theory is adopted for the two flanges. For stress assessment, the stress assessment path is shown in Figure 7. Paths are built along the thickness direction at 11 discrete locations (stress concentration locations) in flanges and flanges and pipes.The stress level of the flange body is classified by the path and the strength is evaluated. That is, when the $\mathrm{PL}+\mathrm{Pb} \leqq 1.5 \mathrm{Sm}$ and the $\mathrm{PL}+\mathrm{Pb}+\mathrm{Q} \leqq 3 \mathrm{Sm}$ are simultaneously satisfied at the discontinuous position, the flange strength is considered to be safe. Among them, $\mathrm{PL}+\mathrm{Pb}$ is a local film stress plus bending stress. A local film stress actually consists of two parts, namely the film stress in the primary overall film stress and the edge stress [18]. Q is the secondary stress, and Sm is the basic permit. With stress intensity. The path 7-7 is away from the path of the discontinuous area, and it is considered that the bending stress is a bending stress, the first film stress + first bending stress meets the allowable value of 1.5 times, and the rest of the paths take the flange discontinuous position, flange thickness direction, etc. Dangerous location.

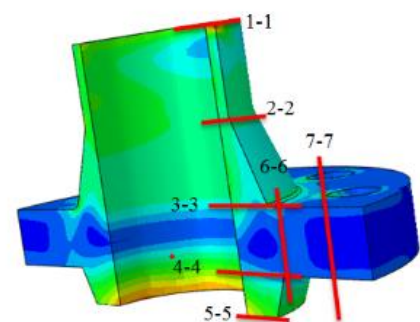

(a) Main flange path

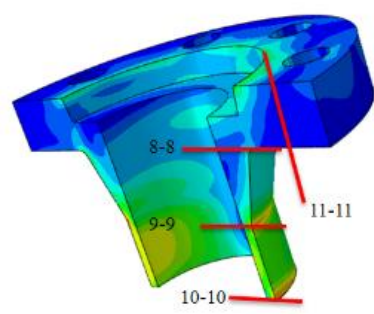

(b)Salve flange path
Figure 7: Flange stress evaluation path

Table 2: Stress assessment table for standard flange under 2500N $\cdot \mathrm{m}$ bending moment (Unit MPa)

\begin{tabular}{|c|c|c|c|c|c|c|c|c|}
\hline Stress & $1-1$ & $2-2$ & $3-3$ & $4-4$ & $5-5$ & $6-6$ & $\begin{array}{l}\text { Allowable } \\
\text { stress }\end{array}$ & $\begin{array}{l}\text { Evaluation } \\
\text { Results }\end{array}$ \\
\hline $\mathrm{PL}+\mathrm{Pb}$ & 213.13 & 133.63 & 40.89 & 21.43 & 46.47 & 4.92 & $1.5 \mathrm{Sm}=225$ & pass \\
\hline $\mathrm{PL}+\mathrm{Pb}+\mathrm{Q}$ & 305.59 & 199.63 & 56.44 & 25.57 & 53.89 & 18.74 & $3 \mathrm{Sm}=450$ & pass \\
\hline Stress & $7-7$ & $8-8$ & $9-9$ & $10-10$ & $11-11$ & \multicolumn{2}{|c|}{ Allowable stress } & $\begin{array}{l}\text { Evaluation } \\
\text { Results }\end{array}$ \\
\hline $\mathrm{PL}+\mathrm{Pb}$ & 6.09 & 37.00 & 135.09 & 127.06 & 54.05 & \multicolumn{2}{|c|}{$1.5 \mathrm{Sm}=225$} & pass \\
\hline $\mathrm{PL}+\mathrm{Pb}+\mathrm{Q}$ & & 72.89 & 200.87 & 227.56 & 112.46 & \multicolumn{2}{|c|}{$3 \mathrm{Sm}=450$} & pass \\
\hline
\end{tabular}


Table 3: Stress assessment table for lightweight flanges under 2500N·m bending moment (Unit MPa)

\begin{tabular}{|l|l|l|l|l|l|l|l|l|}
\hline Stress & $1-1$ & $2-2$ & $3-3$ & $4-4$ & $5-5$ & $6-6$ & $\begin{array}{l}\text { Allowable } \\
\text { stress }\end{array}$ & $\begin{array}{l}\text { Evaluation } \\
\text { Results }\end{array}$ \\
\hline $\begin{array}{l}\mathrm{PL}+\mathrm{Pb} \\
\mathrm{PL}+\mathrm{Pb}+ \\
\mathrm{Q}\end{array}$ & 214.89 & 140.56 & 50.09 & 28.90 & 59.41 & 5.78 & $1.5 \mathrm{Sm}=225$ & pass \\
& 293.59 & 173.41 & 61.21 & 36.03 & 64.18 & 21.46 & $3 \mathrm{Sm}=450$ & pass \\
\hline Stress & $7-7$ & $8-8$ & $9-9$ & $10-10$ & $11-11$ & Allowable stress & $\begin{array}{l}\text { Evaluation } \\
\text { Results }\end{array}$ \\
\hline $\begin{array}{l}\mathrm{PL}+\mathrm{Pb} \\
\mathrm{PL}+\mathrm{Pb}+ \\
\mathrm{Q}\end{array}$ & 5.93 & 52.36 & 124.11 & 127.22 & 89.08 & $1.5 \mathrm{Sm}=225$ & pass \\
pass
\end{tabular}

Tables 2 and 3 show the results of flange stress assessment for two sizes under $2500 \mathrm{~N} \cdot \mathrm{m}$ bending moment. It can be seen from Tables 2 and 3 that both sizes of flanges can pass the strength check, but local positions such as path 8-8 from the corner of the flanged cone neck and the flange, the standard double wedge angle ring gasket method The primary stress and secondary stress of the blue are both lower than those of the double wedge angle ring gasket flange, in which the secondary stress is $74 \mathrm{MPa}$, because the radial thickness of the lightweight flange at the large end of the flanged cone neck is reduced by $4.6 \mathrm{Mm}$, ie, the thinning of the wall thickness makes the discontinuity effect at the corners of the flanged cone neck and the flange more prominent and brings about a higher stress concentration. Similarly, the reason for the large difference between the secondary stresses in path 11-11 is also caused by the thinning of the wall thickness. Finally, although the double-wedge ring gasket flange has a higher stress level in the local position $(8-8,11-11)$, it can still pass the strength check.

\section{REFERENCE}

[1] Zhu, S.C., Liu, X.D., Liu, W.M. 2016. Analysis on flange joints with NiTi gasket under bending using FEM. Journal of Solid Rocket Technology, 39 (05), 685-691.

[2] Kurokouchi, S., Okabe, M., Morita, S. 2001. Taper-seal type metal sealing system and available applications. Applied Surface Sciences, 169$170(2), 799-802$.

[3] Ryota, M. 2009. Analysis of Contact Pressure Distribution on 3-Bolt Self-Energized Connector Seals. ASME 2009 Pressure Vessels and Piping Conference, 71-79.

[4] Gardner, C., Madazhy, R., Howard, E. 2010. Analysis of Contact Pressure Distribution on a Pass Partition Gasket in Conjunction with a DoubleTapered Seal in a High-Pressure Heat Exchanger Closure. ASME 2010 Pressure Vessels and Piping Division/K-PVP Conference. American Society of Mechanical Engineers, 9, 297-303.

[5] Systems and methods for making connections between pipe sections to form a conduit that is substantially free of gaps.

[6] Han, Y., Li, G.H., Yuan, L.F. 2008. Application of Taper -Lok Flanges on
Subsea Pipelines. Oil Field Equipment, 37 (06), 88-89.

[7] Liu, Z.F., Zhang, Y.T., Yan, G.H. 2010. Application of Taper-Lok Flange in the South China Sea Marine Connection. China Water Transport (the second half of the month), (10), 223-225.

[8] Lu, X.F., Xu, Y.J. 2014. Significant analysis and design on the structure parameters of a new double wedge angle ring gasket. Journal of Solid Rocket Technology, (02), 247-252.

[9] Lu, J. 2017. Flange Weight Reduction Based on Self-tightening Doublewedge Angle Rings. Nanjing University of Technology.

[10] Zhu, S.C., Lu, X.F., Gong, J.M. 2012. Effect of Al cover thickness on contact stress of Al-NiTi gasket using FEM. Journal of Solid Rocket Technology, 35 (05), 683-687.

[11] Xu, Y.J., Lu, X.F. 2013.Effect of structure parameters of a new double wedge angle ring gasket on its seal contact pressure. Journal of Solid Rocket Technology, 36 (06), 805-810.

[12] GB 150-2011. "Steel Pressure Vessel" .

[13] Listed, N. 1900. American Society of Mechanical Engineers. Mineralogical Society of America.

[14] Lu, J.C. 2012. High-temperature Flange Strength and Seal Analysis Based on Creep. East China University of Science and Technology.

[15] JB/T4732-2005 Steel Pressure Vessels - Analysis Design Standard.

[16] Qin, S.J. 2013. Several Discussions on Stress Classification Methods. Chemical Engineering Equipment and Piping, 50 (02), 1-7.

[17] De'nan, F., Nazri, F.M., Hashim, N.S. 2017. Finite Element Analysis on Lateral Torsional Buckling Behaviour Oi I-Beam with Web Opening. Engineering Heritage Journal, 1 (2), 19-22.

[18] Shaikh, M.M., AlSuhaimi, A.O., Hanafiah, M.M., Ashraf, M.A., Fantoukh, A., AlHarbi, E. 2017. Leachable Volatile Organic Compounds from Polyethylene Plumbing Plastic Pipes: a case study of Medina $\mathrm{Al}$ Munawarah, Saudi Arabia. Acta Chemica Malaysia, 1 (1), 01-03. 